OPEN ACCESS

Edited by: József Tímár,

Semmelweis University, Hungary

${ }^{*}$ Correspondence:

Sarah Adel Hakim

sarahadel2003@yahoo.com

Received: 28 August 2020 Accepted: 03 February 2021

Published: 09 April 2021

Citation:

Hakim SA and Abou Gabal HH (2021) Diagnostic Utility of BAP1, EZH2 and

Survivin in Differentiating Pleural Epithelioid Mesothelioma and Reactive Mesothelial Hyperplasia: Immunohistochemical Study. Pathol. Oncol. Res. 27:600073. doi: 10.3389/pore.2021.600073

\section{Diagnostic Utility of BAP1, EZH2 and Survivin in Differentiating Pleural Epithelioid Mesothelioma and Reactive Mesothelial Hyperplasia: Immunohistochemical Study}

\author{
Sarah Adel Hakim* and Hoda Hassan Abou Gabal \\ Department of Pathology, Faculty of Medicine, Ain Shams University, Cairo, Egypt
}

Background: Epithelioid mesothelioma (EM) is the commonest subtype of malignant pleural mesothelioma. Its histopathological discrimination from reactive mesothelial hyperplasia $(\mathrm{RMH})$ could be challenging. Thus, an immunohistochemical panel is mandatory for better discrimination. BAP1 is a newly identified diagnostic marker whose loss is specific to malignant mesothelioma. EZH2 overexpression is reported in different cancers, but its relation to BAP1 in malignant mesothelioma has not been fully understood. Survivin expression is said to be significantly higher in EM than in nonneoplastic pleural tissue, but its diagnostic utility as an immunohistochemical marker has not been thoroughly investigated in this field. To the best of our knowledge, no previous studies have been conducted to assess the diagnostic accuracy of the combined use of these three nuclear markers (BAP1, EZH2 and Survivin) in discriminating pleural EM from $\mathrm{RMH}$.

Methods: This retrospective study includes two groups: 81 cases of pleural EM and 67 cases of $\mathrm{RMH}$, retrieved from the archives of Pathology Department of Ain Shams University Hospitals and Ain-Shams University Specialized Hospital during the period from January 2016 to December 2019. An immunohistochemical study was performed using BAP1, EZH2 and Survivin antibodies.

Results: There were highly statistically significant relations between study groups as regards the studied markers ( $p=0.001$ for each). The specificity was $100 \%$ for all combinations of immunohistochemical markers. Sensitivity of any combination of the immunohistochemical markers used in this study was found to be higher than the sensitivity of any of these markers used individually. The combination of all three markers showed the highest diagnostic accuracy (95.9\%) and the highest sensitivity (92.6\%). However, the combination of Survivin and EZH2 yielded the same diagnostic accuracy and sensitivity.

Conclusion: Adding EZH2, Survivin and BAP1 to the diagnostic IHC panel for differentiating pleural EM and $\mathrm{RMH}$ could enhance diagnostic sensitivity. Moreover, 
Survivin is a potentially promising marker in this context, especially when combined with $\mathrm{EZH} 2$.

Keywords: mesothelioma, reactive mesothelial hyperplasia, BAP1, EZH2, survivin, immunohistochemistry

\section{INTRODUCTION}

Pleural malignant mesothelioma poses a diagnostic challenge that may cause late diagnosis at an advanced stage. Being an extremely aggressive cancer, it requires a highly sensitive and specific panel of immunohistochemical markers capable of early and definitive diagnosis [1].

BRCA1-associated protein 1 (BAP1) is a newly identified diagnostic marker whose loss is specific to malignant mesothelioma $[2,3]$. BAP1 expression was recorded in up to $77 \%$ of epithelioid mesothelioma (EM). BAP1 loss is caused by mutations, deletions or epigenetic silencing of BAP1 in both familial and sporadic malignant mesothelioma. It encodes ubiquitin C-terminal hydrolase that may have a role in keeping the appropriate ubiquitination status of target histones. Nonetheless, the definite role of BAP1 loss in malignant transformation of mesothelial cells is still ambiguous to a great extent [4].

It was demonstrated that BAP1 loss promoted cell proliferation in vitro through up-regulation of enhancer of zeste 2 polycomb repressive complex two subunit (EZH2) [5]. EZH2 encodes a histone-lysine $\mathrm{N}$-methyltransferase that functions as a transcriptional repressor. EZH2 overexpression was reported in different cancers, such as prostatic cancer, breast cancer, and uterine cancer, and had worse prognosis in some cancers [6]. In malignant mesothelioma, it was demonstrated that EZH2 mRNA expression was elevated, yet EZH2 IHC expression and its association with BAP1 in malignant mesothelioma have not been fully understood.

Although the primary function of EZH2 is gene silencing through the methylation of $\mathrm{H} 3 \mathrm{~K} 27$, most evidence shows that $\mathrm{EZH} 2$ functions independently of $\mathrm{H} 3 \mathrm{~K} 27 \mathrm{me} 3$ in various cancers; for instance, in some cancers EZH2 was shown to interact with $\beta$-catenin and promote its nuclear accumulation and activation [7], to form the $\beta$-catenin/T-cell factor (TCF) transcriptional activator, which up-regulates a number of target genes such as survivin, c-Myc and VEGF [8]. It was reported that the level of mRNA expression of baculoviral IAP repeatcontaining 5 (BIRC5; Survivin) was significantly higher in EM than in non-neoplastic pleural tissue [9], although the utility of Survivin IHC in differentiating benign and malignant mesothelial proliferation has not yet been thoroughly investigated.

To the best of our knowledge, no previous studies were conducted to assess the diagnostic accuracy of the combined use of BAP1, EZH2 and Survivin in discriminating pleural epithelioid mesothelioma from reactive mesothelial hyperplasia. Thus, the current study aims at assessing their diagnostic utility, combined together, in different pairs, and individually while comparing the diagnostic accuracy in each condition.

\section{MATERIAL AND METHODS}

\section{Tissue and Patient Data}

The current study was conducted on two groups: 81 cases of pleural epithelioid mesothelioma (EM) and 67 cases with reactive mesothelial hyperplasia (RMH). Cases of both groups were obtained from the archives of the Pathology Lab. of AinShams University Specialized Hospital and Ain-Shams University Hospitals. The study cases were diagnosed during the period from January 2016 to December 2019; and cases of both groups were obtained via thoracoscopic pleural biopsy. The histopathology reports were reviewed to determine age and sex of patients. Haematoxylin and Eosin stained slides were examined to re-evaluate and verify the histopathologic diagnosis. In addition, samples from the EM group were evaluated to determine growth pattern, degree of nuclear atypia, presence of necrosis and tumor grading using two-tier system [10]. International Mesothelioma Interest Group (IMIG) staging [11] was available for the EM cases included in the study. Only primary samples of EM patients who did not receive prior neoadjuvant therapy as well as samples with enough tissue and information on all covariates were selected in the analysis.

\section{Ethics Statement}

All patients who participated in this study signed a written informed consent before thoracoscopic pleural biopsy. The study was approved by the Research Ethical Committee at Faculty of Medicine, Ain Shams University.

\section{Immunohistochemical Staining}

Four micrometer sections of formalin-fixed and paraffinembedded samples of pleural EM and RMH were prepared. Immunohistochemical staining was performed using primary antibodies: rabbit polyclonal anti-Survivin (Clone: AF886; R\&D systems, MN, United States; dilution of 1:200); mouse monoclonal anti-BAP1 (Clone: C-4; Santa Cruz Biotechnology, Santa Cruz, CA, United States; 1:100 dilution) and mouse monoclonal anti-EZH2 (11) (Clone: 415M-18; Cell Marque, Sigma-Aldrich Co.,CA, United States; 1:100 dilution). AvidinBiotin immunoperoxidase complex technique was used according to the study of $\mathrm{Hsu}$ et al. [12], by applying the super sensitive detection kit (Biogenex, CA, United States). The prepared tissue sections were fixed on poly-L- lysine coated slides overnight at $37^{\circ} \mathrm{C}$. They were deparaffinized and rehydrated through graded alcohol series. Then the sections were heated in a microwave oven in $10 \mathrm{mM}$ citrate buffer ( $\mathrm{pH}$ 6.0) for $20 \mathrm{~min}$. After the blocking of endogenous peroxidase and incubation in Protein Block Serum-Free Solution (Dako Cytomation, Glostrup, Denmark) for $20 \mathrm{~min}$, the sections were incubated overnight at $4^{\circ} \mathrm{C}$ with primary antibodies. 
TABLE 1 | Comparison between the two study groups as regards personal data.

\begin{tabular}{|c|c|c|c|c|c|c|c|}
\hline & & \multicolumn{4}{|c|}{ Group } & \multirow[t]{3}{*}{$p$} & \multirow[t]{3}{*}{ Sig } \\
\hline & & \multicolumn{2}{|c|}{ Pleural mesothelioma } & \multicolumn{2}{|c|}{ RMH } & & \\
\hline & & Mean & \pm SD & Mean & $\pm \mathrm{SD}$ & & \\
\hline \multirow{2}{*}{\multicolumn{2}{|c|}{ Age }} & 67.9 & 3.4 & 47.4 & 2.3 & $0.001^{a}$ & $\mathrm{HS}$ \\
\hline & & $\mathbf{N}$ & $\%$ & $\mathbf{N}$ & $\%$ & & \\
\hline \multirow[t]{2}{*}{ Gender } & Male (n \%) & 64 & $79.0 \%$ & 59 & $88.1 \%$ & $0.144^{b}$ & NS \\
\hline & Female (n \%) & 17 & $21.0 \%$ & 8 & $11.9 \%$ & & \\
\hline
\end{tabular}

astudent $t$ test.

${ }^{b}$ Chi-Square Tests.

Biotinylated anti-mouse immunoglobulin and streptavidin conjugated to horseradish peroxidase were then added. Finally, $3,3^{\prime}$-diaminobenzidine, as the substrate or chromogen, was used to form an insoluble brown product. Finally, the sections were counterstained with hematoxylin and mounted. With each run, sections of human pancreas tissue, breast invasive duct carcinoma and non-Hodgkin lymphoma (NHL) were used as a positive control for BAP-1, EZH2 and Survivin respectively [12-14]. Negative control sections were incubated with normal mouse serum instead of the three primary antibodies.

\section{Interpretation of Immunohistochemical Staining}

Immunohistochemical analysis of BAP1, EZH2 and Survivin was blindly performed by the two pathologists (the authors) without any prior knowledge of the clinicopathological data. Any discrepancies were resolved by consensus using a multi-head microscope.

Nuclear staining of BAP1, EZH2 and Survivin in EM or RMH cells with similar or higher intensity, as positive control tissue, was regarded as positive staining. For BAP1, negative staining was defined as completely absent nuclear staining in the target cells [16].

Immunoreactivity for EZH2 was divided into two groups; no/ low expression (proportion of cells $<50 \%$; which included EZH2 null with a cut-off of $<10 \%$ positive tumor cells and low EZH2 with a cut-off of $10-49 \%$ positive tumor cells), or high expression (proportion of cells of $\geq 50 \%$ ). This was done for easier statistical analysis and guided by previous papers $[4,15]$.

Immunoreactivity for Survivin was evaluated using a labeling index (\% of positive cells) in the "hot spot" exhibiting the highest number of positive cells compared to the rest of the lesion. At least $100 \mathrm{EM}$ or $\mathrm{RMH}$ cells in high power fields $(\times 400)$ were evaluated. Independent counting of labeling indices of Survivin was performed by the two pathologists (the authors), then the mean of the two evaluations was calculated [13]. The cut-off value for the Survivin IHC evaluation was set at $5 \%$ guided by a previous study [16]; hence, immunoreactivity of Survivin was classified as negative (positivity of less than $5 \%$ of mesothelioma cells or non-neoplastic mesothelial cells), or positive (positivity of $\geq 5 \%$ of the target cells).

Some background inflammatory cells/stromal cells showed positivity for these nuclear markers and served as internal positive control. Careful observation under high power magnification was

\begin{tabular}{|c|c|c|c|c|c|}
\hline & & Mean & $\pm \mathrm{SD}$ & Minimum & Maximum \\
\hline \multirow[t]{2}{*}{ Age } & & 67.88 & 3.44 & 60.00 & 74.00 \\
\hline & & $\mathbf{N}$ & $\%$ & & \\
\hline \multirow[t]{2}{*}{ Gender } & Male & 65 & $80.2 \%$ & & \\
\hline & Female & 16 & $19.8 \%$ & & \\
\hline \multirow[t]{3}{*}{ Growth pattern } & Solid & 46 & $56.8 \%$ & & \\
\hline & Tubulopapillary & 29 & $35.8 \%$ & & \\
\hline & Trabecular & 6 & $7.4 \%$ & & \\
\hline \multirow[t]{2}{*}{ Two-tier grade } & Low & 67 & $82.7 \%$ & & \\
\hline & High & 14 & $17.3 \%$ & & \\
\hline \multirow{2}{*}{$\begin{array}{l}\text { Presence of } \\
\text { necrosis }\end{array}$} & Absent & 57 & $70.4 \%$ & & \\
\hline & Present & 24 & $29.6 \%$ & & \\
\hline \multirow{3}{*}{$\begin{array}{l}\text { Degree of } \\
\text { nuclear atypia }\end{array}$} & Mild & 8 & $9.9 \%$ & & \\
\hline & Moderate & 59 & $72.8 \%$ & & \\
\hline & Severe & 14 & $17.3 \%$ & & \\
\hline \multirow[t]{2}{*}{ IMIG stage } & Early stages (I/II) & 42 & $51.9 \%$ & & \\
\hline & $\begin{array}{l}\text { Late stages } \\
(\mathrm{III} / \mathrm{IV})\end{array}$ & 39 & $48.1 \%$ & & \\
\hline
\end{tabular}

performed in all cases for better discrimination of tumor cells. Any interobserver variance was decided by consensus using a multi-head microscope.

\section{Statistical Analysis}

Continuous variables are expressed as mean and Standard Deviation. Categorical variables are expressed as frequencies and percent points. Student $t$ test was used to assess the statistical significance of the difference between two study group mean. Chi square and Fisher's exact test were used to examine the relationship between Categorical variables. A significance level of $p<0.05$ was used in all tests. All statistical procedures were carried out using SPSS version 15 for Windows (SPSS Inc., Chicago, IL, United States).

\section{RESULTS}

\section{Clinicopathological Characteristics}

The study includes 81 cases of pleural epithelioid mesothelioma (EM) and 67 cases of reactive mesothelial (RMH) hyperplasia. Sixty-four out of the 81 EM cases are males and 17 are females; and out of the $67 \mathrm{RMH}, 59$ cases are males, while only eight are 


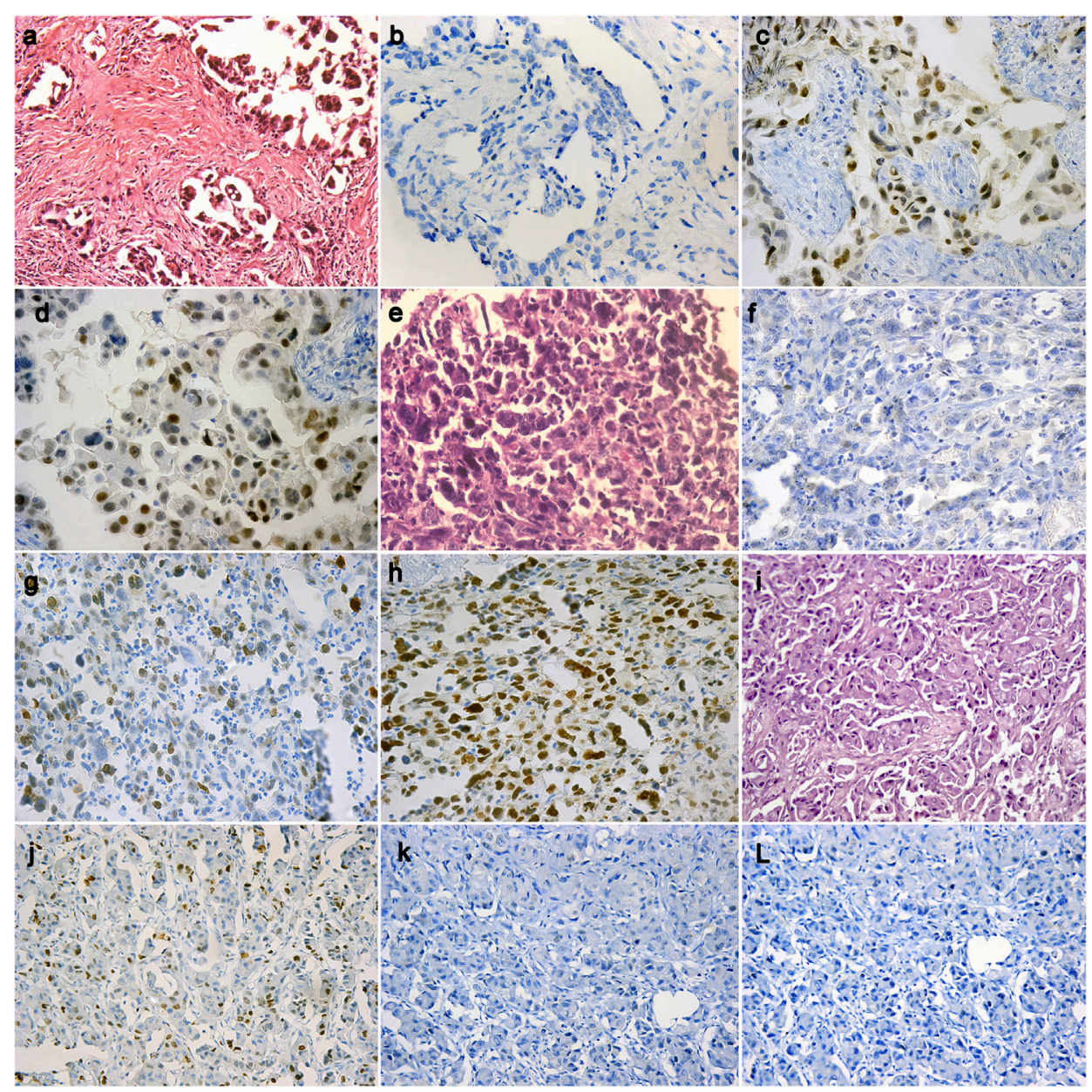

FIGURE 1 | A case of epithelioid mesothelioma $(\mathrm{H} \& \mathrm{E} \times 20) \mathbf{( A )}$, BAP1 loss in tumor cells $(\mathrm{IHC} \times 40)(\mathbf{B})$, High EZH2 nuclear expression in tumor cells (IHC $\times 40)(\mathbf{C})$, Positive Survivin expression in tumor cells $(\mathrm{IHC} \times 40)(\mathbf{D})$; A case of epithelioid mesothelioma (H\&E $\times 40)(\mathbf{E})$, BAP1 loss in tumor cells (IHC $\times 20)(\mathbf{F})$, Low EZH2 nuclear expression in tumor cells $(\mathrm{IHC} \times 20) \mathbf{( G )}$, Positive Survivin expression in tumor cells $(\mathrm{IHC} \times 20)(\mathbf{H})$; A case of epithelioid mesothelioma (H\&E $\times 20)(\mathbf{I})$, BAP1 retained in tumor cells $(\mathrm{IHC} \times 20) \mathbf{( J )}$, Negative EZH2 nuclear expression in tumor cells $(\mathrm{IHC} \times 20) \mathbf{( K )}$, Negative Survivin expression in tumor cells $(\mathrm{IHC} \times 20) \mathbf{( L )}$.

females. The mean age of $\mathrm{EM}$ is 67.9 years $(\mathrm{SD} \pm 3.4)$, while the mean age of $\mathrm{RMH}$ is 47.4 years $(\mathrm{SD} \pm 2.3)$.

There is a highly significant difference among the study groups as regards age where EM was observed among older age groups. No significant difference was observed with respect to gender as males are predominant in both groups (Table 1).

Concerning the EM group, data distribution of clinicopathological parameters are summarized in Table 2.

\section{Immunohistochemical Results}

Forty-nine (60.5\%) out of the 81 cases of pleural EM reveal BAP1 homogenous expression loss pattern (Figures 1B,F) while the rest of the cases show retained BAP1 nuclear expression (Figure 1J) (Table 3). On the other hand, all $67 \mathrm{RMH}$ cases show retained BAP1 nuclear expression (Figure 2B).

Thirty-six (44.4\%) out of 81cases of pleural EM show high EZH2 nuclear expression (Figure 1C). However, none of the 67 cases of RMH show high EZH2 nuclear expression (Figure 2C,D),
(Table 3). No EZH2 expression could be detected in the adjacent normal mesothelial cells.

Fifty-five (67.9\%) out of 81 cases of pleural EM show positive Survivin nuclear expression (Figure 1D,H). However, all 67 cases of RMH show negative Survivin nuclear expression (Figure 2E), (Table 3).

There is a highly significant difference between study groups and the studied markers; individually and in different combinations as shown in Table 3.

\section{Sensitivity and Specificity of the Immunohistochemical Markers}

The sensitivity and specificity of each marker for discriminating pleural EM from RMH cases was summarized in Table 4. All of Survivin positivity, BAP1 loss, and high expression of EZH2 expressed in cases of EM had $100 \%$ specificity, and their sensitivities were $67.9,60.5$, and $44.4 \%$, respectively.

The specificity was $100 \%$ for all combinations of immunohistochemical markers. Sensitivity of any combination 
TABLE 3 | Comparison between the two study groups as regard studied markers individually and in combinations.

\begin{tabular}{|c|c|c|c|c|c|c|c|}
\hline & & \multicolumn{4}{|c|}{ Group } & \multirow[t]{3}{*}{$p$} & \multirow[t]{3}{*}{ Sig } \\
\hline & & \multicolumn{2}{|c|}{$\begin{array}{c}\text { Pleural } \\
\text { mesothelioma } \\
\end{array}$} & \multicolumn{2}{|c|}{ RMH } & & \\
\hline & & $\mathbf{N}$ & $\%$ & $\mathbf{N}$ & $\%$ & & \\
\hline \multirow[t]{2}{*}{ Survivin $\mathrm{IHC}$ expression } & Positive & 55 & 67.9 & 0 & 0.0 & 0.001 & HS \\
\hline & Negative & 26 & 32.1 & 67 & 100.0 & & \\
\hline \multirow[t]{2}{*}{ BAP1 IHC expression } & Loss & 49 & 60.5 & 0 & 0.0 & 0.001 & HS \\
\hline & Retained & 32 & 39.5 & 67 & 100.0 & & \\
\hline \multirow[t]{2}{*}{ EZH2 IHC expression } & High & 36 & 44.4 & 0 & 0.0 & 0.001 & HS \\
\hline & No/Low & 45 & 55.6 & 67 & 100.0 & & \\
\hline \multirow[t]{3}{*}{ EZH2 IHC expression } & High & 36 & 44.4 & 0 & 0.0 & $0.001^{a}$ & HS \\
\hline & Low & 32 & 39.5 & 7 & 10.4 & & \\
\hline & Null & 13 & 16.1 & 60 & 89.6 & & \\
\hline \multirow[t]{2}{*}{ Survivin-positive and/or BAP1-loss } & Positive & 61 & 75.3 & 0 & 0.0 & $0.001^{a}$ & HS \\
\hline & Negative & 20 & 24.7 & 67 & 100.0 & & \\
\hline \multirow[t]{2}{*}{ Survivin-positive and/or EZH2-High expression } & Positive & 75 & 92.6 & 0 & 0.0 & $0.001^{a}$ & HS \\
\hline & Negative & 6 & 7.4 & 67 & 100.0 & & \\
\hline \multirow[t]{2}{*}{ BAP1-loss and/or EZH2-High expression } & Positive & 69 & 85.2 & 0 & 0.0 & $0.001^{a}$ & HS \\
\hline & Negative & 12 & 14.8 & 67 & 100.0 & & \\
\hline \multirow[t]{2}{*}{ Survivin-positive and/or BAP1-loss and/or EZH2-High expression } & Positive & 75 & 92.6 & 0 & 0.0 & $0.001^{a}$ & $\mathrm{HS}$ \\
\hline & Negative & 6 & 7.4 & 67 & 100.0 & & \\
\hline
\end{tabular}

${ }^{a}$ Chi-Square Tests

of the immunohistochemical markers used in this study is higher than the sensitivity of any of these markers alone. Although the combination of all three markers showed the highest diagnostic accuracy (95.9\%) and the highest sensitivity (92.6\%), still the combination of only Survivin and EZH2 yielded the same diagnostic accuracy and sensitivity, which showed that adding BAP1 to the combination did not improve the diagnostic accuracy or sensitivity (Table 4 ).

\section{Association Between the Immunohistochemical Markers}

There was a highly statistically significant association between positive Survivin IHC expression and BAP1 loss among mesothelioma cases, as $78 \%$ of positive Survivin cases had BAP1 loss compared to $23.1 \%$ only of negative Survivin IHC expression cases that manifested BAP1 loss IHC expression (Figure 3A). Also, a high statistically significant association between EZH2 and Survivin ( $p=0.001)$ is detected, where $70.9 \%$ of positive Survivin malignant mesothelioma cases are associated with low EZH2 expression and high EZH2 expression in malignant mesothelioma is associated with negative Survivin expression in $76.9 \%$ of cases (Figure 3B). There was a statistically significant association between BAP1 and EZH2 expression ( $p=0.008$ ), where $67.3 \%$ of cases of BAP1 loss showed low EZH2 and $62.5 \%$ of malignant mesothelioma cases with retained BAP1 showed high EZH2 expression (Figure 3C).

\section{Relationship Between the Studied Markers and Clinicopathological Parameters in EM Group}

Comparing IHC expression of the three studied markers to clinicopathological parameters of EM (growth pattern, two-tier

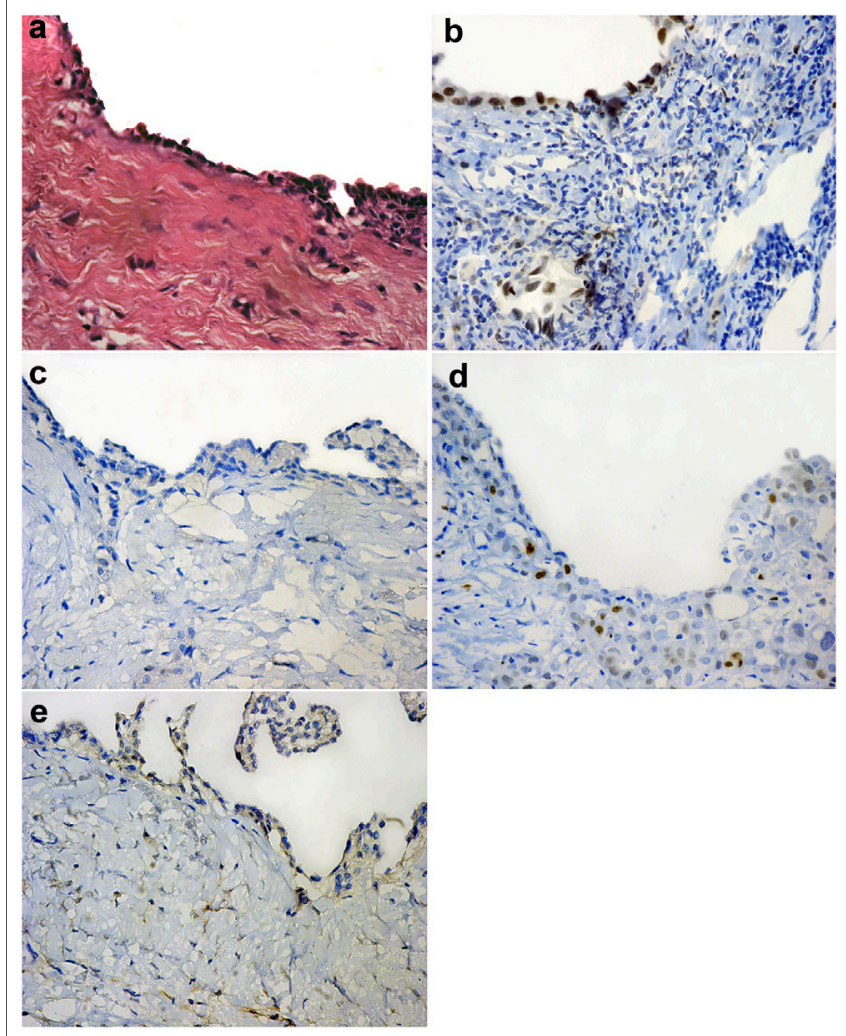

FIGURE 2 | Reactive mesothelial hyperplasia $(H \& E \times 40)$ (A), Positive BAP-1 nuclear expression in reactive mesothelial cells $(\mathrm{IHC} \times 40)(B)$, Negative EZH2 nuclear expression in reactive mesothelial cells $(\mathrm{IHC} \times 40)$ (C), Low EZH2 nuclear expression in reactive mesothelial cells (IHC $\times 40)$ (D), Negative Survivin nuclear expression in reactive mesothelial cells $(\mathrm{IHC} \times 40)(\mathbf{E})$. 
TABLE 4 | Diagnostic utility of studied markers in malignant mesothelioma; individually and in combinations.

\begin{tabular}{|c|c|c|c|c|c|}
\hline & Sensitivity (\%) & Specificity (\%) & PPV (\%) & NPV (\%) & Accuracy (\%) \\
\hline Survivin positive & 67.9 & 100.0 & 100.0 & 72.0 & 82.4 \\
\hline BAP1-loss & 60.5 & 100.0 & 100.0 & 67.65 & 78.3 \\
\hline $\mathrm{EZH} 2$ high expression & 44.4 & 100.0 & 100.0 & 59.8 & 69.5 \\
\hline Survivin-positive and/or BAP1-loss & 75.30 & 100 & 100 & 77 & 86.5 \\
\hline Survivin-positive and/or EZH2-High expression & 92.60 & 100 & 100 & 91.7 & 95.9 \\
\hline BAP1-loss and/or EZH2-High expression & 85.20 & 100 & 100 & 84.8 & 91.9 \\
\hline Survivin-positive and/or BAP1-loss and/or EZH2-High expression & 92.60 & 100 & 100 & 91.7 & 95.9 \\
\hline
\end{tabular}

Bold values indicate combinations with the highest diagnostic accuracy.

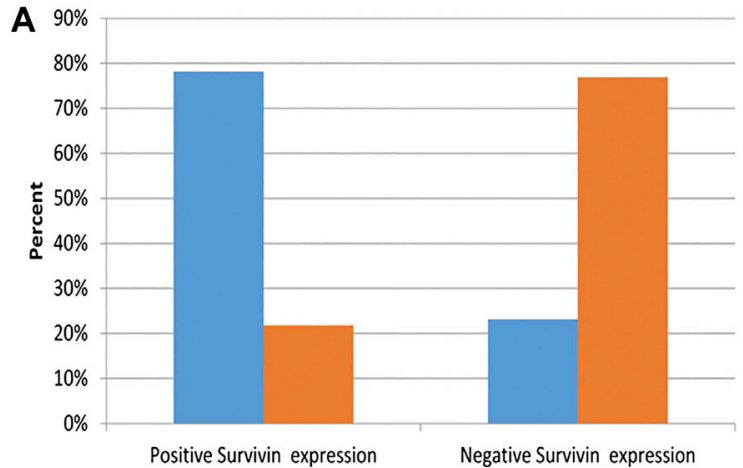

BAP-1 IHC expression

C

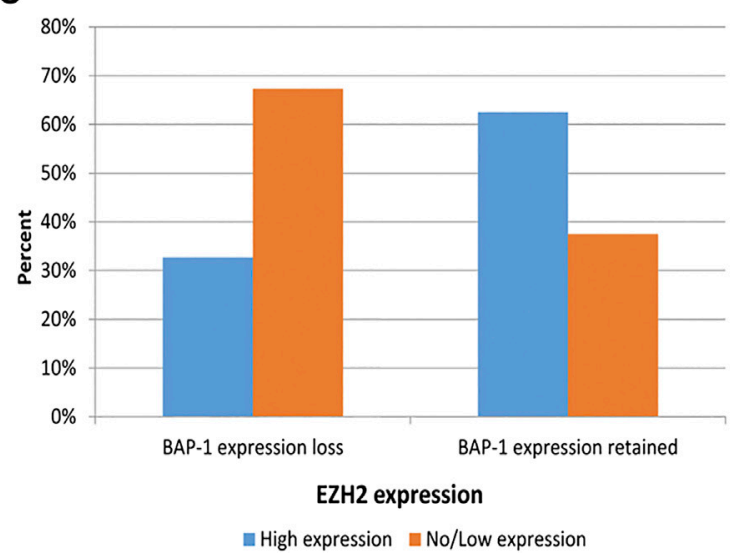

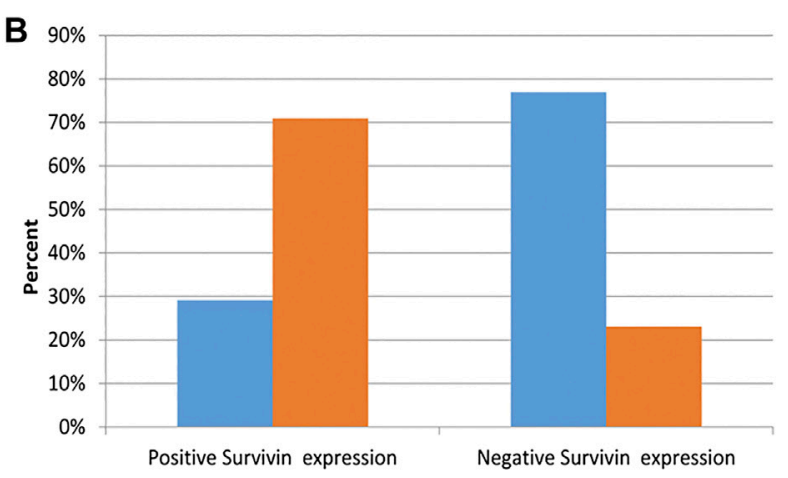

EZH2 expression

High expression No/Low expression

FIGURE 3 | Association between Survivin IHC and BAP1 IHC expression among EM cases (A), Association between Survivin IHC and EZH2 IHC expression among EM cases (B), Association between BAP1 $1 \mathrm{HC}$ expression and EZH2 $\Vdash H C$ expression among EM (C).

system of grading, presence of necrosis, degree of nuclear atypia, IMIG staging) reveals no statistically significant relationships (Tables 5-7).

\section{DISCUSSION}

Accurate histopathological differentiation between malignant pleural mesothelioma (MPM) and reactive mesothelial hyperplasia $(\mathrm{RMH})$ is extremely crucial [16]. The commonest subtype of MPM is epithelioid mesothelioma (EM), constituting about $50-70 \%$ of all cases of MPM [17]. EM shows variable degrees of architectural complexity and cytological atypia; therefore, cases of EM are not always easily distinguished from cases of RMH, especially in the instances where tumor cells have bland nuclei proliferating in tubulo-trabecular pattern with minimal stromal invasion. On the other hand, $\mathrm{RMH}$ could show severe proliferation of mesothelial cells with worrisome nuclear features. It usually shows no evidence of stromal invasion, yet care needs to be taken in assessing this as mesothelial entrapment may occur especially in inflammatory processes [4]. Therefore, to obtain a better diagnostic panel for EM, this 
study evaluated the diagnostic utilities of BAP1, EZH2 and Survivin in distinguishing EM from RMH.

BAP1 is a relatively new marker for the diagnosis of malignant mesothelioma and its utility has been demonstrated in several studies. The frequency of BAP1 loss demonstrated in EM cases in the present study was $60.5 \%$, whereas none of the cases of RMH showed BAP1 loss. This was similar to what was previously reported by Shinzaki-Ushiku et al., who demonstrated BAP1 loss in $61 \%$ of their EM cases [4]. However, the percentage is somewhat lower than what was reported by Kushitani et al., whose frequency of BAP1 loss was $66.2 \%$ in EM; though their results agreed with those of the present study with respect to $\mathrm{RMH}$ cases, which also showed no BAP1 loss in any of them [18-20].

Concerning the pattern of staining of BAP1, in the current study, all EM cases had either a uniform positive nuclear staining pattern or completely negative nuclear staining for BAP1. This was similar to the pattern described by Kushitani et al. [16], but was different from that of Hida et al. [18] who demonstrated focal heterogenous BAP1 staining pattern in their mesothelioma cases. This may be attributed to the presence of inflammatory cells infiltrating into the mesothelioma or stromal cells that necessitate careful observation under high power magnification. Other reasons, such as differences in staining techniques and improper processing of the tumor may also contribute to the apparent differences among the studies.

High EZH2 expression has been described in various cancer types $[6,7]$, but only a few studies have investigated EZH2 expression in malignant mesothelioma [4, 5, 15, 21]. High EZH2 expression was demonstrated in $44.4 \%$ of the cases of malignant mesothelioma in the current study; which is less than what was recorded in ShinozakiUshiku et al. [4], whose frequency of high EZH2 expression was $57 \%$, but was similar to the percentage reported in Yoshimura et al. [15], whose malignant mesothelioma cases showed high EZH2 expression in $44.7 \%$. However, concerning $\mathrm{RMH}$ cases, previous papers $[4,15]$ including our current study, showed that none of the $\mathrm{RMH}$ cases showed high EZH2 expression, instead all showed no or low EZH2 expression.

Concerning Survivn expression in the current study, positive Survivin expression was detected in $67.9 \%$ of malignant mesothelioma cases, but none of the RMH cases showed Survivin positivity. This was similar to the finding previously described in Meerang et al. [22], who demonstrated Survivin positivity in $67.7 \%$ of their cases, while none of their cases of RMH showed Survivin expression. On the other hand, our results were lower than those reported by Hmeljak et al. [23], who detected nuclear Survivin positivity in $100 \%$ of their tumor samples.

Any discrepancies among different papers in the frequency of expression of any of the markers utilized in the current paper may be due to different sample sizes, differences in staining techniques, source of antibodies used for analysis, and the quantification technique. In our current study, we used fully automated immunohistochemical staining and commercially available antibodies from reputable sources. In addition, evaluation of nuclear reactivity was independently confirmed by both pathologists (the authors) of this study.

A combination of any two of the markers utilized in this study showed higher sensitivity compared to the individual use of either marker, whereas all combinations had $100 \%$ specificity; positive Survivin/BAP1 loss combination showed $75.3 \%$ sensitivity. This was unlike the percentage reported by Kushitani et al. [16], where positive Survivin and/or BAP1 loss combination showed a different sensitivity of $89.8 \%$ but similar specificity of $100 \%$ - the difference is probably due to different sample size and different techniques.

The current study reported that high EZH2 and/or BAP1 loss had $85.2 \%$ sensitivity. This was lower than the sensitivity reported by Shinozaki-Ushiku et al. [4] to the same combination (90\%) but with similar specificity (100\%), this could be attributed to the fact that they worked on both biphasic as well as epithelioid mesothelioma. The cases of this study, however, were only epithelioid mesothelioma. On the other hand, the sensitivity reported by Yoshimura et al. [15] (73.7\%) was lower than that reported in the current paper, probably due to their relatively smaller sample size.

In the present study, the highest sensitivity for a combination of two markers was among high EZH2 and/or positive Survivin which reached $92.6 \%$, with $100 \%$ specificity and $95.5 \%$ accuracy. To the best of our knowledge, this is the first study to assess the combined use of EZH2 and Survivin in malignant mesothelioma and RMH cases.

There was an inverse association between high EZH2 expression and each of BAP1 loss and positive Survivin expression. This inverse association enabled the combinations with high EZH2 (namely high EZH2 and/or BAP1 loss and high EZH2 and/or positive Survivin) to offer increased sensitivity in the differential diagnosis between EM and RMH (sensitivity of 85.2 and $92.6 \%$ respectively). These inverse associations might suggest that mechanisms underlying high EZH2 expression, BAP1 loss, and positive Survivin in EM may be distinct and need further elucidation. On the other hand, there was a highly significant direct association between BAP1 loss and positive Survivin, which might explain why their combination showed the least sensitivity $75.3 \%$.

Concerning clinicopathological parameters of EM, emerging data has recommended the preferential use of two-tier grading of EM, IMIG stage and the need for commenting on the histological growth pattern of EM $[10,11,24]$. In our cohort of EM samples, we did not find any statistically significant relationships between the studied markers (BAP1, EZH2 and Survivin) and clinicopathological parameters of EM (growth pattern, two-tier grading, presence of necrosis, degree of nuclear atypia and IMIG stage). Interestingly, the frequency of EZH2, Survivin and BAP1 expression was similar in both low grade and high grade mesotheliomas, as well as in various growth patterns indicating that the combination of these markers is equally or similarly sensitive among all these morphological variants.

It is worth noting that most of the established markers for diagnosing malignant mesothelioma express cytoplasmic staining with variable intensity which makes it sometimes challenging to discriminate from non-specific staining. Thus, another advantage of the immunohistochemical markers (BAP1, EZH2 and Survivin) used in the current study is that they are all nuclear markers. New diagnostic immunohistochemical markers and techniques are needed for cases where established IHC markers cannot provide a clear entity diagnosis, and to improve treatment of malignant mesothelioma.

A recent study has shown a promising role for the loss of nuclear 5hydroxymethylcytosine (5-hmC) immunohistochemical expression in mesothelioma, but stated that the need for new immunohistochemical markers still exists [25]. Therefore, the current study has demonstrated that using these new markers for malignant mesothelioma could greatly improve the diagnostic accuracy $[26,27]$. 
TABLE 5 | Correlation between BAP1 IHC expression and clinicopathological parameters of EM group.

\begin{tabular}{|c|c|c|c|c|c|c|c|}
\hline & & \multicolumn{4}{|c|}{ BAP1 IHC expression } & \multirow[t]{3}{*}{$p$} & \multirow[t]{3}{*}{ Sig } \\
\hline & & \multicolumn{2}{|c|}{ Negative } & \multicolumn{2}{|c|}{ Positive } & & \\
\hline & & Mean & \pm SD & Mean & \pm SD & & \\
\hline \multirow[t]{2}{*}{ Age } & & 67.98 & 3.51 & 67.72 & 3.39 & $0.741^{\mathrm{a}}$ & NS \\
\hline & & $\mathrm{N}$ & $\%$ & $\mathrm{~N}$ & $\%$ & & \\
\hline \multirow[t]{2}{*}{ Gender } & Male & 40 & $81.6 \%$ & 25 & $78.1 \%$ & $0.698^{\mathrm{b}}$ & NS \\
\hline & Female & 9 & $18.4 \%$ & 7 & $21.9 \%$ & & \\
\hline \multirow[t]{3}{*}{ Growth pattern } & Solid & 28 & $57.1 \%$ & 18 & $56.3 \%$ & $0.880^{C}$ & NS \\
\hline & Tubulopapillary & 18 & $36.7 \%$ & 11 & $34.4 \%$ & & \\
\hline & Trabecular & 3 & $6.1 \%$ & 3 & $9.4 \%$ & & \\
\hline \multirow[t]{2}{*}{ Two-tier grade } & Low & 42 & $85.7 \%$ & 25 & $78.1 \%$ & $0.377^{\mathrm{b}}$ & NS \\
\hline & High & 7 & $14.3 \%$ & 7 & $21.9 \%$ & & \\
\hline \multirow[t]{2}{*}{ Presence of necrosis } & Absent & 34 & $69.4 \%$ & 23 & $71.9 \%$ & $0.811^{\mathrm{b}}$ & NS \\
\hline & Present & 15 & $30.6 \%$ & 9 & $28.1 \%$ & & \\
\hline \multirow[t]{3}{*}{ Degree of nuclear atypia } & Mild & 6 & $12.2 \%$ & 2 & $6.3 \%$ & $0.525^{c}$ & NS \\
\hline & Moderate & 36 & $73.5 \%$ & 23 & $71.9 \%$ & & \\
\hline & Severe & 7 & $14.3 \%$ & 7 & $21.9 \%$ & & \\
\hline \multirow[t]{2}{*}{ IMIG stage } & Early stages (I/II) & 28 & $57.1 \%$ & 14 & $43.8 \%$ & $0.238^{\mathrm{b}}$ & NS \\
\hline & Advanced stages (III/IV) & 21 & $42.9 \%$ & 18 & $56.3 \%$ & & \\
\hline
\end{tabular}

${ }^{a}$ Student $t$ test.

${ }^{b}$ Chi-Square Tests.

${ }^{c}$ Fisher's exact test.

TABLE 6 | Correlation between EZH2 IHC expression and clinicopathological parameters of EM group.

\begin{tabular}{|c|c|c|c|c|c|c|c|}
\hline & & \multicolumn{4}{|c|}{ EZH2 IHC expression } & \multirow[t]{3}{*}{$p$} & \multirow[t]{3}{*}{ Sig } \\
\hline & & \multicolumn{2}{|c|}{ No/Low } & \multicolumn{2}{|c|}{ High } & & \\
\hline & & Mean & $\pm \mathrm{SD}$ & Mean & $\pm \mathrm{SD}$ & & \\
\hline \multirow[t]{2}{*}{ Age } & & 68.18 & 3.08 & 67.50 & 3.86 & $0.382^{\mathrm{a}}$ & NS \\
\hline & & $N$ & $\%$ & $\mathrm{~N}$ & $\%$ & & \\
\hline \multirow[t]{2}{*}{ Gender } & Male & 35 & $77.8 \%$ & 30 & $83.3 \%$ & $0.533^{b}$ & NS \\
\hline & Female & 10 & $22.2 \%$ & 6 & $16.7 \%$ & & \\
\hline \multirow[t]{3}{*}{ Growth pattern } & Solid & 26 & $57.8 \%$ & 20 & $55.6 \%$ & $1.0^{\mathrm{C}}$ & NS \\
\hline & Tubulopapillary & 16 & $35.6 \%$ & 13 & $36.1 \%$ & & \\
\hline & Trabecular & 3 & $6.7 \%$ & 3 & $8.3 \%$ & & \\
\hline \multirow[t]{2}{*}{ Two-tier grade } & Low & 40 & $88.9 \%$ & 27 & $75.0 \%$ & $0.100^{b}$ & NS \\
\hline & High & 5 & $11.1 \%$ & 9 & $25.0 \%$ & & \\
\hline \multirow[t]{2}{*}{ Presence of necrosis } & Absent & 35 & $77.8 \%$ & 22 & $61.1 \%$ & $0.103^{b}$ & NS \\
\hline & Present & 10 & $22.2 \%$ & 14 & $38.9 \%$ & & \\
\hline \multirow[t]{3}{*}{ Degree of nuclear atypia } & Mild & 7 & $15.6 \%$ & 1 & $2.8 \%$ & $0.070^{c}$ & NS \\
\hline & Moderate & 33 & $73.3 \%$ & 26 & $72.2 \%$ & & \\
\hline & Severe & 5 & $11.1 \%$ & 9 & $25.0 \%$ & & \\
\hline \multirow[t]{2}{*}{ IMIG stage } & Early stages (I/II) & 30 & $66.7 \%$ & 12 & $33.3 \%$ & $0.003^{b}$ & HS \\
\hline & Advanced stages (III/IV) & 15 & $33.3 \%$ & 24 & $66.7 \%$ & & \\
\hline
\end{tabular}

${ }^{a}$ Student $t$ test

${ }^{b}$ Chi-Square Tests.

${ }^{c}$ Fisher's exact test.

Though it was beyond the scope of the current study, yet we found it intriguing to review the literature to find out the frequency of BAP1 loss, Survivin and EZH2 positivity in other malignancies that might pose differential diagnostic challenges with EM. While BAP1 loss was very rare in breast carcinoma [28], pancreatic ductal adenocarcinoma [29], non-small cell lung cancer [30] and colorectal adenocarcinoma [31], EZH2 positivity, on the other hand, was detected in advanced metastatic non-small cell lung cancer [32], $50 \%$ of primary pancreatic adenocarcinoma [33], more than $73.7 \%$ of primary colorectal carcinoma [34] and $49.8 \%$ of primary breast cancer [35]. Survivin was expressed in the cytoplasm of tumor cells in 59.3\% of breast cancer [36] and $76.9 \%$ of pancreatic adenocarcinoma [37]. On the other hand, non-small cell lung cancer and colorectal cancer express Survivin nuclear positivity in 48.3 and $63.2 \%$ of tumor cells respectively $[38,39]$. Further studies comparing the expression of BAP1, Survivin and EZH2 in different metastatic tumors and EM should be conducted.

One limitation of the present study is that it included pleural epithelioid mesothelioma and reactive mesothelial hyperplasia, the former being the commonest type of malignant mesothelioma and 
TABLE 7 | Correlation between Survivin IHC expression and clinicopathological parameters of EM group.

\begin{tabular}{|c|c|c|c|c|c|c|c|}
\hline & & \multicolumn{4}{|c|}{ Survivin IHC expression } & \multirow[t]{3}{*}{$p$} & \multirow[t]{3}{*}{ Sig } \\
\hline & & \multicolumn{2}{|c|}{ Negative } & \multicolumn{2}{|c|}{ Positive } & & \\
\hline & & Mean & \pm SD & Mean & $\pm S D$ & & \\
\hline \multirow[t]{2}{*}{ Age } & & 68.65 & 3.52 & 67.51 & 3.38 & $0.164^{a}$ & NS \\
\hline & & $\mathrm{N}$ & $\%$ & $\mathrm{~N}$ & $\%$ & & \\
\hline \multirow[t]{2}{*}{ Gender } & Male & 21 & $80.8 \%$ & 44 & $80.0 \%$ & $0.935^{\mathrm{b}}$ & NS \\
\hline & Female & 5 & $19.2 \%$ & 11 & $20.0 \%$ & & \\
\hline \multirow[t]{3}{*}{ Growth pattern } & Solid & 14 & $53.8 \%$ & 32 & $58.2 \%$ & $0.880^{\mathrm{C}}$ & NS \\
\hline & Tubulopapillary & 9 & $34.6 \%$ & 20 & $36.4 \%$ & & \\
\hline & Trabecular & 3 & $11.5 \%$ & 3 & $5.5 \%$ & & \\
\hline \multirow[t]{2}{*}{ Two-tier grade } & Low & 21 & $80.8 \%$ & 46 & $83.6 \%$ & $0.750^{\mathrm{b}}$ & NS \\
\hline & High & 5 & $19.2 \%$ & 9 & $16.4 \%$ & & \\
\hline \multirow[t]{2}{*}{ Presence of necrosis } & Absent & 18 & $69.2 \%$ & 39 & $70.9 \%$ & 0.877 & NS \\
\hline & Present & 8 & $30.8 \%$ & 16 & $29.1 \%$ & & \\
\hline \multirow[t]{3}{*}{ Degree of nuclear atypia } & Mild & 2 & $7.7 \%$ & 6 & $10.9 \%$ & 0.525 & NS \\
\hline & Moderate & 19 & $73.1 \%$ & 40 & $72.7 \%$ & & \\
\hline & Severe & 5 & $19.2 \%$ & 9 & $16.4 \%$ & & \\
\hline \multirow[t]{2}{*}{ IMIG stage } & Early stages (I/II) & 15 & $57.7 \%$ & 27 & $49.1 \%$ & 0.469 & NS \\
\hline & Advanced stages (III/IV) & 11 & $42.3 \%$ & 28 & $50.9 \%$ & & \\
\hline
\end{tabular}

${ }^{a}$ Student $t$ test.

${ }^{b}$ Chi-Square tests.

${ }^{c}$ Fisher's exact test.

the latter being its mimic, however, more studies should be conducted involving other mesothelioma subtypes, other benign mesothelial lesions as well as other tumors of the pleura and metastatic tumors that pose diagnostic challenges.

In conclusion, adding EZH2, Survivin and BAP1 to the diagnostic IHC panel for differentiating pleural EM and $\mathrm{RMH}$ would increase the diagnostic sensitivity. Furthermore, the current study highlighted the promising potential diagnostic role of Survivin, especially when combined with EZH2, in discriminating pleural EM from RMH.

\section{DATA AVAILABILITY STATEMENT}

The original contributions presented in the study are included in the article/Supplementary Material, further inquiries can be directed to the corresponding author.

\section{REFERENCES}

1. Churg A, Sheffield BS, Galateau-Salle F. New markers for separating benign from malignant mesothelial proliferations: are we there yet? Arch Pathol Lab Med (2016). 140(4):318-21. doi:10.5858/arpa.2015-0240-SA

2. Testa JR, Cheung M, Pei J, Below JE, Tan Y, Sementino E., et al. Germline BAP1 mutations predispose to malignant mesothelioma. Nat Genet (2011). 43(10): 1022-5. doi:10.1038/ng.912

3. Bott M, Brevet M, Taylor BS, Shimizu S, Ito T, Wang L., et al. The nuclear deubiquitinase BAP1 is commonly inactivated by somatic mutations and 3p21.1 losses in malignant pleural mesothelioma. Nat Genet (2011). 43(7):668-72. doi:10.1038/ng.855

4. Shinozaki-Ushiku A, Ushiku T, Morita S, Anraku M, Nakajima J, Fukayama M. Diagnostic utility of BAP1 and EZH2 expression in malignant mesothelioma. Histopathology (2017). 70:722-33. doi:10.1111/his.13123

5. LaFave LM, Béguelin W, Koche R, Teater M, Spitzer B, Chramiec A., et al. Loss of BAP1 function leads to EZH2-dependent transformation. Nat Med (2015). 21(11):1344-9. doi:10.1038/nm.3947

\section{AUTHOR CONTRIBUTIONS}

$\mathrm{SH}$ : conceived, designed and coordinated the study, performed data collection and statistical analysis, reviewed the histological diagnosis, evaluated immunohistochemistry, and drafted the manuscript. HA: participated in the study design, reviewed the histological diagnosis, evaluated immunohistochemistry, carried out photographing, coordinated and critically reviewed the manuscript. The authors read and approved the final manuscript.

\section{CONFLICT OF INTEREST}

The authors declare that the research was conducted in the absence of any commercial or financial relationships that could be construed as a potential conflict of interest.

6. Kim KH, Roberts CW. Targeting EZH2 in cancer. Nat Med (2016). 22(2): 128-34. doi:10.1038/nm.4036

7. Yamaguchi H, Hung MC. Regulation and role of EZH2 in cancer. Cancer Res Treat (2014). 46(3):209-22. doi:10.4143/crt.2014.46.3.209

8. Chen X, Duan N, Zhang C, Zhang W. Survivin and tumorigenesis: molecular mechanisms and therapeutic strategies. J Cancer (2016). 7:314-23. doi:10.7150/ jca.13332

9. Kushitani K, Amatya VJ, Mawas AS, Miyata Y, Okada M, Takeshima Y. Use of anti-noxa antibody for differential diagnosis between epithelioid mesothelioma and reactive mesothelial hyperplasia. Pathobiology (2016). 83(1):33-40. doi:10. $1159 / 000442092$

10. Nicholson AG, Sauter JL, Nowak AK, Kindler HL, Gill RR, Remy-Jardin M., et al. EURACAN/IASLC proposals for updating the histologic classification of pleural mesothelioma: towards a more multidisciplinary approach. J Thorac Oncol (2020). 15(1):29-49. doi:10.1016/j.jtho.2019.08.2506

11. Husain AN, Colby TV, Ordóñez NG, Allen TC, Attanoos RL, Beasley MB., et al. Guidelines for pathologic diagnosis of malignant mesothelioma 2017 update of the consensus statement from the international mesothelioma 
interest group. Arch Pathol Lab Med (2018). 142(1):89-108. doi:10.5858/arpa. 2017-0124-RA

12. Hsu SM, Raine L, Fanger H. Use of avidin-biotin-peroxidase complex (ABC) in immunoperoxidase techniques: a comparison between $\mathrm{ABC}$ and unlabeled antibody (PAP) procedures. J Histochem Cytochem (1981). 29:577-80. doi:10. $1177 / 29.4 .6166661$

13 Vassallo J, Al Saati T, Gascoyne RD, Welsh K, Reed JC, Brousset P., et al. Immunoexpression of Survivin in non-neoplastic lymphoid tissues and malignant lymphomas using a new monoclonal antibody reactive on paraffin sections. J Hematop (2010). 3:3-9. doi:10.1007/s12308-009-0054-8

14. Farquhar N, Thornton S, Coupland SE, Coulson JM, Sacco JJ, Krishna Y., et al. Patterns of BAP1 protein expression provide insights into prognostic significance and the biology of uveal melanoma. J Pathol Clin Res (2018). 4:26-38. doi: $10.1002 / \mathrm{cjp} 2.86$

15. Yoshimura M, Kinoshita Y, Hamasaki M, Matsumoto S, Hida T, Oda Y., et al. Highly expressed EZH2 in combination with BAP1 and MTAP loss, as detected by immunohistochemistry, is useful for differentiating malignant pleural mesothelioma from reactive mesothelial hyperplasia. Lung Cancer (2019). 130:187-93. doi:10.1016/j.lungcan.2019.02.004

16. Kushitani K, Amatya VJ, Mawas AS, Suzuki R, Miyata Y, Okada M., et al. Utility of survivin, BAP1, and ki-67 immunohistochemistry in distinguishing epithelioid mesothelioma from reactive mesothelial hyperplasia. Oncol Lett (2018). 15:3540-7. doi:10.3892/ol.2018.7765

17. Rossini M, Rizzo P, Bononi I, Clementz A, Ferrari R, Martini F., et al. New perspectives on diagnosis and therapy of malignant pleural mesothelioma. Front Oncol (2018). 8:91. doi:10.3389/fonc.2018.00091

18. Hida T, Hamasaki M, Matsumoto S, Sato A, Tsujimura T, Kawahara K., et al. BAP1 immunohistochemistry and p16 FISH results in combination provide higher confidence in malignant pleural mesothelioma diagnosis: ROC analysis of the two tests. Pathol Int (2016). 66(10):563-70. doi:10.1111/ pin. 12453

19. Hwang HC, Sheffield BS, Rodriguez S, Thompson K, Tse CH, Gown AM., et al. Utility of BAP1 immunohistochemistry and p16 (CDKN2A) FISH in the diagnosis of malignant mesothelioma in effusion cytology specimens. Am J Surg Pathol (2016). 40(1):120-6. doi:10.1097/PAS. 0000000000000529

20. Cigognetti M, Lonardi S, Fisogni S, Balzarini P, Pellegrini V, Tironi A., et al. BAP1 (BRCA1-associated protein 1) is a highly specific marker for differentiating mesothelioma from reactive mesothelial proliferations. Mod Pathol (2015). 28(8):1043-57. doi:10.1038/modpathol.2015.65

21. Ang PP, Tan GC, Karim N, Wong YP Diagnostic value of the EZH2 immunomarker in malignant effusion cytology. Acta Cytol (2020). 64: 248-55. doi:10.1159/000501406

22. Meerang M, Bérard K, Friess M, Bitanihirwe BK, Soltermann A, Vrugt B., et al. Low merlin expression and high survivin labeling index are indicators for poor prognosis in patients with malignant pleural mesothelioma. Mol Oncol (2016). 10(8):1255-65. doi:10.1016/j.molonc.2016.06.005

23. Hmeljak J, Erčulj N, Dolžan V, Pižem J, Kern I, Kovač V., et al. Is survivin expression prognostic or predictive in malignant pleural mesothelioma? Virchows Arch (2013). 462(3):315-21. doi:10.1007/s00428-013-1373-9

24. Bilecz A, Stockhammer P, Theegarten D, Kern I, Jakopovic M, Samarzija M., et al. Comparative analysis of prognostic histopathologic parameters in subtypes of epithelioid pleural mesothelioma. Histopathology (2020). 77(1): 55-66. doi:10.1111/his.14105

25. Chapel DB, Husain AN, Krausz T. Immunohistochemical evaluation of nuclear 5-hydroxymethylcytosine $(5-\mathrm{hmC})$ accurately distinguishes malignant pleural mesothelioma from benign mesothelial proliferations. Mod Pathol (2019). 32(3):376-86. doi:10.1038/s41379-018-0159-7

26. Sandeck HP, Røe OD, Kjærheim K, Willén H, Larsson E. Re-evaluation of histological diagnoses of malignant mesothelioma by immunohistochemistry. Diagn Pathol (2010). 5:47. doi:10.1186/1746-1596-5-47

27. Lin F, Chen Z. Standardization of diagnostic immunohistochemistry: literature review and geisinger experience. Arch Pathol Lab Med (2014). 138(12): 1564-77. doi:10.5858/arpa.2014-0074-RA

28. Chui J, Singh A, Gill AJ Loss of BAP1 expression is very rare in breast carcinoma. Pathology (2017). 49(5):557-60. doi:10.1016/j.pathol.2017.03.008

29. Tayao M, Andrici J, Farzin M, Clarkson A, Sioson L, Watson N., et al. Loss of BAP1 expression is very rare in pancreatic ductal adenocarcinoma. PLoS One (2016). 11:e0150338. doi:10.1371/journal.pone.0150338

30. Andrici J, Parkhill TR, Jung J, Wardell KL, Verdonk B, Singh A., et al. Loss of expression of BAP1 is very rare in non-small cell lung carcinoma. Pathology (2016). 48(4):336-40. doi:10.1016/j.pathol.2016.03.005

31. Chui J, Verdonk B, Gill AJ. Loss of BAP1 expression occurs rarely to never in colorectal adenocarcinoma. Appl Immunohistochem Mol Morphol (2018). 26(9):e91-e92. doi:10.1097/PAI.0000000000000506

32. Behrens C, Solis LM, Lin H, Yuan P, Tang X, Kadara H., et al. EZH2 protein expression associates with the early pathogenesis, tumor progression, and prognosis of non-small cell lung carcinoma. Clin Cancer Res (2013). 19(23): 6556-65. doi:10.1158/1078-0432.CCR-12-3946

33. Han T, Jiao F, Hu H, Yuan C, Wang L, Jin ZL., et al. EZH2 promotes cell migration and invasion but not alters cell proliferation by suppressing E-cadherin, partly through association with MALAT-1 in pancreatic cancer. Oncotarget (2016). 7(10):11194-207. doi:10.18632/oncotarget. 7156

34. Abdel Raouf SM, Ibrahim TR, Abdelaziz LA, Farid MI, Mohamed SY. Prognostic value of TWIST1 and EZH2 expression in colon cancer. J Gastrointest Cancer (2019). 52:90-98. doi:10.1007/s12029-019-00344-4

35. Jang SH, Lee JE, Oh MH, Lee JH, Cho HD, Kim KJ., et al. High EZH2 protein expression is associated with poor overall survival in patients with luminal A breast cancer. J Breast Cancer (2016). 19(1):53-60. doi:10.4048/jbc.2016.19. 1.53

36. Chu JS, Shew JY, Huang CS. Immunohistochemical analysis of survivin expression in primary breast cancers. J Formos Med Assoc (2004). 103(12):925-31.

37. Satoh K, Kaneko K, Hirota M, Masamune A, Satoh A, Shimosegawa T. Expression of survivin is correlated with cancer cell apoptosis and is involved in the development of human pancreatic duct cell tumors. Cancer (2001). 92(2):271-8. doi:10.1002/1097-0142(20010715)92:2<271::aidcncr1319>3.0.co;2-0

38. Atikcan S, Unsal E, Demirag F, Köksal D, Yilmaz A. Correlation between survivin expression and prognosis in non-small cell lung cancer. Respir Med (2006). 100(12):2220-6. doi:10.1016/j.rmed.2006.02.031

39. Jakubowska K, Pryczynicz A, Dymicka-Piekarska V, Famulski W, GuzińskaUstymowicz K. Immunohistochemical expression and serum level of survivin protein in colorectal cancer patients. Oncol Lett (2016). 12:3591-7. doi:10. 3892/ol.2016.5075

Copyright $(2021$ Hakim and Abou Gabal. This is an open-access article distributed under the terms of the Creative Commons Attribution License (CC BY). The use, distribution or reproduction in other forums is permitted, provided the original author(s) and the copyright owner(s) are credited and that the original publication in this journal is cited, in accordance with accepted academic practice. No use, distribution or reproduction is permitted which does not comply with these terms. 